\title{
Simulation of Water Allocation Optimization Problem
}

\author{
Rudy Agustriyanto \\ Chemical Engineering Department, University of Surabaya \\ Jl. Raya Kalirungkut, Surabaya, 60293 \\ Email: rudy.agustriyanto@staff.ubaya.ac.id
}

\begin{abstract}
Pollution prevention is primarily stimulated by economics, legislation, liability concerns, and the enhanced environmental benefit of managing waste at source. Chemical process industries consume a huge amount of water. Consequently, wastewater streams from such industries which contain various contaminants may create environmental problem. The increasing cost of fresh water supply and wastewater treatment has encouraged process industries to minimize fresh water consumption and waste water generation. This paper presents a formulation of water allocation problem (WAP) in order to minimize fresh water consumption in multi contaminant mass exchanger network. The approach is based on mass balance equation within the system being studied. The problem were then solved by using Matlab Optimization Toolbox.
\end{abstract}

Keywords: Optimization, mass exchanger, water allocation

\section{INTRODUCTION}

Optimization (minimization and maximization) is the most common problem to find a set of solution that is optimal from many possible solutions [11].

Water minimization techniques in the process design can simultaneously reduce overall fresh and waste water involved in the process. Hierarchy strategies that can be used to reduce waste within a process are as follows [5],[7]:

- Source reduction

This include: modification of equipment, changes in process design and operation, reformulation and redesign of products, substitution of raw materials and use of green technology.

- Recycle / reuse

Typically this strategy involves separation technology to recover valuable materials such as solvents, metals, inorganic species and water.

- $\quad$ End-of pipe treatment

The application of chemical, biological and physical process to reduce waste toxicity and volume to meet environmental regulation.

- Ultimate disposal 
Post process activities which handle waste such as deep well injection and off site shipment of hazardous material to waste management facilities.

Similar approaches are also proposed by Wang and Smith [4] to minimize water consumption which in turn will reduce wastewater quantity. These approaches are:

- Process changes

This approach may reduce the quantity of overall process water required. For example: using air coolers instead of cooling towers.

- Re-use

Wastewater from one unit operation can be directly re-used in other unit if The level of previous contamination does not interfere with operation. This might require waste water being mixed with fresh water and / or waste water from other unit.

- Regeneration re-use

When the wastewater is refined and reused in another operation or process. It will also be frequently mixed with wastewater from other unit of fresh water

- Regeneration re-cycling

Wastewater can be regenerated to remove contaminants which have built up and is then recycled. In this case water can re-enter processes in which it has previously used.

\section{RELATED WORKS}

Doyle and Smith [2] studied two cases of water reuse containing various contaminants. The mass transfer was modeled in terms of fixed mass load for the first case and in the second case the mass transfer was modeled in terms of fixed outlet concentration. This leads to an optimization problem which can be solved as a non-linear (for the first case) and linear programming (for the second case). Srinophakun et al [10] studied water-waste water optimization in tapioca starch manufacturing using nonlinear programming (NLP). The optimization problem was then solved by high level modeling language. Wang and Smith [3] used mass transfer-based approach of pinch technology to solve water minimization problem for mass exchanger network. Saeedi and Hosseinzadeh [8] utilized Lingo software to obtain the solution of water optimization using linear and non linear programming. Li and Chang [6] developed an efficient initialization strategy to solve the NLP and MINLP models for synthesizing water using networks with multiple contaminants.

This paper presents the practical formulation of nonlinear programming (NLP) using a case study for multiple contaminants in a mass exchangers network system for water / wastewater allocation problem. The focus is only recycle/ reuse of water through the chemical process as an 
integrated system. This NLP type can be effectively solved by using commercial optimizer available.

\section{ORIGINALITY}

A Computer with Matlab software installed. The optimization calculation were performed by using Optimization Toolbox in Matlab. To the author knowledge, up to now none solve the problem using Optimization Toolbox of Matlab. It is simple but powerfull.

\section{SYSTEM DESIGN}

According to El-Halwagi [5], a mass exchanger is any direct-contact mass-transfer unit that employs a mass separating agent (or a lean phase) to selectively remove certain components (e.g., contaminants) from a rich phase (e.g., a waste stream). The following unit operations are considered as examples of mass exchanger: absorption, adsorption, extraction, ion exchange, leaching and stripping. The main objective of a mass exchanger is to provide appropriate contact surface for the rich and lean phases. Although various configurations are exist, counter-current systems are mostly adopted due to their industrial important and efficiency. Figure 1 shows an isothermal mass exchanger in which the rich (waste stream) $i$, has a flow rate $G \mathrm{i}$ and the contaminants must be reduced from an inlet composition, $C_{i}^{i n}$, to an outlet composition, $C_{i}^{\text {out }}$. The rich stream transfers contaminants into the lean stream whose flowrate $F_{j}$ and inlet composition $C_{j}^{i n}$. The outlet composition of lean stream is $C_{j}^{\text {out }}$.

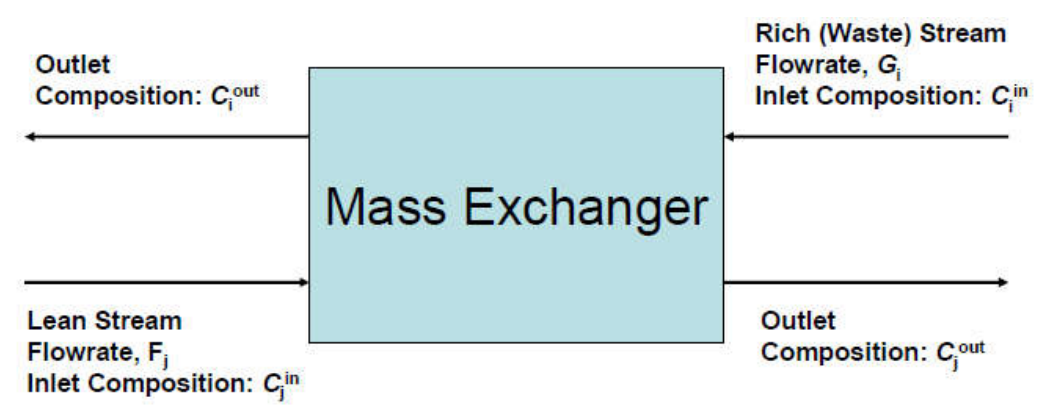

Figure 1. A single mass exchanger

From Figure 1, the mass load or the amount of contaminant to be transferred (M) is:

$$
M=G_{i}\left(C_{i}^{\text {in }}-C_{i}^{\text {out }}\right)=F_{j}\left(C_{i}^{\text {out }}-C_{i}^{\text {in }}\right)
$$

The problem formulation begins with a mass exchanger system in which contaminants were transferred from rich stream into water as a lean stream. The contaminants could be total suspended solid (TSS), total dissolved solid (TDS), biological oxygen demand (BOD), total organic carbon (TOC), chemical oxygen demand or other contaminant concentration. 
The following assumptions were made:

- All data for the limiting water profiles is available and certain

- The number of unit operations which use water was fixed

- Mass flow rate of each stream were assumed constant

"Given a set of inlet and outlet of water process, it is desired to determine a network of interconnections of water streams among the processes, so that the overall fresh water needed is minimized while all unit operations receive acceptable water quality" [1], [9].

Figure 2 shows water allocation problem for 2 unit mass exchangers. Here for simplification, the rich stream is not depicted since the mass load for contaminants has already been defined (Eq.1). Suppose there are 2 contaminants (i.e. contaminant A and B), then

- There are 2 fresh water streams: $F_{1}$ and $F_{2}$

- There are 2 waste water streams: $W_{1}$ and $W_{2}$

- There are 2 fresh water streams: $F_{1}$ and $F_{2}$

If mass load for the two contaminants are available for each mass exchanger, and limiting concentrations for each component in each stream are also fixed, then the problem is to minimize total amount of fresh water $\left(F_{1}+F_{2}\right)$.

To minimize water consumption, the objective function for this case is: $\min \left(F_{1}+F_{2}\right)$

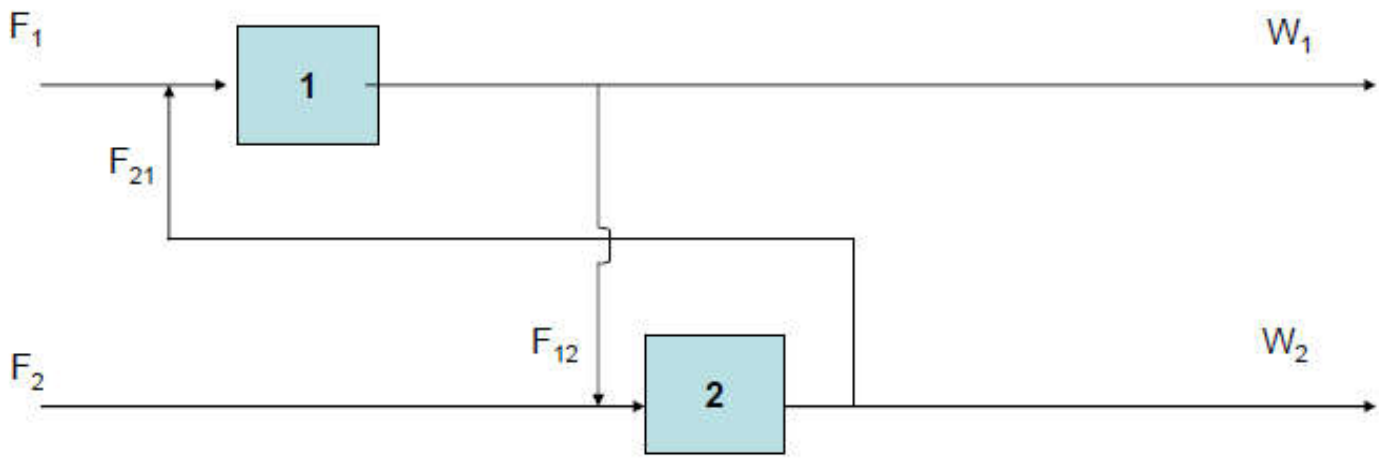

Figure 2. Water allocation problem for 2 unit mass exchangers

Assuming that all data for the limiting water profiles is available and certain, the number of unit operation is fixed (i.e. two) and the mass flow rate of each stream are relatively constant, and then there will be 11 equalities constraints, which consist of:

- Four contaminant mass balances in equipment no.1 and 2:

$$
\begin{aligned}
& F_{21} C_{A 2, \text { out }}+M_{A 1}=\left(W_{1}+F_{12}\right) C_{A 1, \text { out }} \\
& F_{21} C_{B 2, \text { out }}+M_{B 1}=\left(W_{1}+F_{12}\right) C_{B 1, \text { out }}
\end{aligned}
$$




$$
\begin{aligned}
& F_{12} C_{A 1, \text { out }}+M_{A 2}=\left(W_{2}+F_{21}\right) C_{A 2, \text { out }} \\
& F_{12} C_{B 1, \text { out }}+M_{B 2}=\left(W_{2}+F_{21}\right) C_{B 2, \text { out }}
\end{aligned}
$$

- Two total mass balances in equipment no.1 and 2:

$$
\begin{aligned}
& F_{1}+F_{21}+M_{A 1}+M_{B 1}=W_{1}+F_{12} \\
& F_{2}+F_{12}+M_{A 2}+M_{B 2}=W_{2}+F_{21}
\end{aligned}
$$

- Four contaminant mass balances inlet mixing point for equipment no.1 and 2:

$$
\begin{aligned}
& F_{21} C_{A 2, \text { out }}=\left(F_{1}+F_{21}\right) C_{A 1, \text { in }} \\
& F_{21} C_{B 2, \text { out }}=\left(F_{1}+F_{21}\right) C_{B 1, \text { in }} \\
& F_{12} C_{A 1, \text { out }}=\left(F_{2}+F_{12}\right) C_{A 2, \text { in }} \\
& F_{12} C_{B 1, \text { out }}=\left(F_{2}+F_{12}\right) C_{B 2, \text { in }}
\end{aligned}
$$

- One overall mass balance:

$$
F_{1}+F_{2}+M_{A 1}+M_{B 1}+M_{A 2}+M_{B 2}=W_{1}+F_{12}
$$

The non-equalities constraints for this optimization problem are provided from the allowable maximum inlet and outlet concentrations for each of the equipment. Since both flowrate and contaminant concentrations from any mass exchanger need to be determined, hence the nonlinear programing is used to solve Eq. (2) subject to Eq. (3) - (13).

Mathematically, the objective function can be formulated as follows:

$$
\min \sum_{1}^{\mathrm{n}} F_{j}
$$

In general, for $n$ mass exchanger equipment with $k$ number of contaminants, the total number of equalities constraints available is $(2 k+1) n+1$. Therefore, there should be 22 total equalities constraints for the above problem. The equalities constraints that must be satisfied consist of:

- $\quad k$ contaminant mass balances for each of the equipment.

The mass balance for $j^{\text {th }}$ equipment and component $m$ can be written generally as follows:

$\sum_{\mathrm{i} \neq \mathrm{j}}^{\mathrm{n}} F_{i j} C_{m i, o u t}+M_{m j}=\left(W_{j}+\sum_{i \neq j}^{n} F_{i j}\right) C_{m j, o u t}$

Where $F_{i i}=F_{i}$

- One total mass balance for each of the equipment.

The total mass balance of the $j^{\text {th }}$ equipment can be written using the following general expression: 


$$
\sum_{i}^{n} F_{i j}+\sum_{m}^{k} M_{m j}=W_{j}+\sum_{i \neq j}^{n} F_{j i}
$$

- $\quad k$ contaminant mass balances in mixing point for each of the equipment. The mass balance in mixing point for the inlet of the $j^{\text {th }}$ equipment and component $\mathrm{m}$ can be written generally as follows:

$\sum_{i \neq j}^{n} F_{i j} C_{m i, o u t}=\left(\sum_{i}^{n} F_{i j}\right) C_{m j, \text { in }}$

Where $F_{i i}=F_{i}$

- One overall mass balance can be expressed as follows:

$$
\sum_{i}^{n} F_{i}+\sum_{m}^{k} \sum_{i}^{n} M_{m i}=\sum_{i}^{n} W_{i}
$$

The above equations (Eq. (1) to (18)) can be derived from the mass balance principle which were fundamental in chemical engineering.

\section{EXPERIMENT AND ANALYSIS}

Consider the example of multi contaminant water network in three mass exchangers (unit operations), as shown in Figure 3 where all possible reuse water lines are shown and its limiting data is presented in Table 1[3]. The main objective of this problem is to minimize fresh water consumption which satisfies inlet and outlet concentration constraints.

In order to solve this problem (expressed in Eq. (14)), the total mass balance and component mass balances were derived for each of process equipment using Eq. (15) - (18). Moreover, the non-equalities constraints for inlet and outlet contaminant concentration shown in Table 1 were used.

The optimization results are summarized in Figure 4 and Table 2. The minimum fresh water consumption that satisfies all the equalities constraints is 105.63 ton/h. Those results were obtained from system mass balances that were used as equalities constraints, while all lower and upper bounds of inlet and outlet concentrations were used directly as inequalities constraints in minimization problem in the mass exchanger network. 


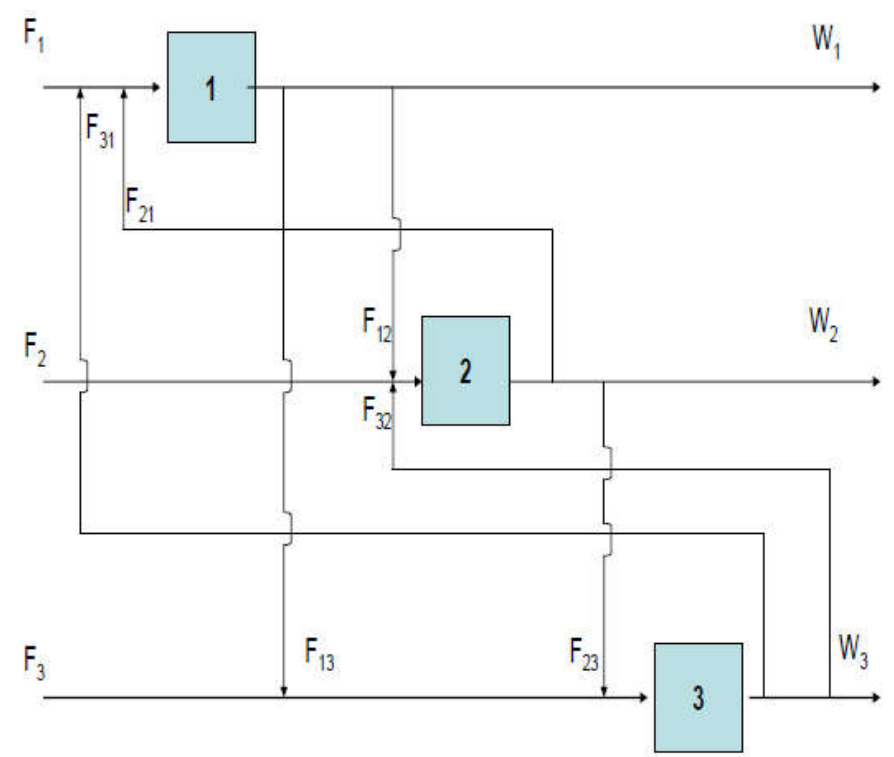

Figure 3. Multi contaminant water network

Table 1. Limiting data for multi contaminant water network.

\begin{tabular}{ccccc}
\hline Process & Contaminant & $\begin{array}{c}\text { M (Mass } \\
\text { Load) } \\
(\mathrm{kg} / \mathrm{h})\end{array}$ & $\begin{array}{c}C_{\text {in }}^{\max } \\
(\mathrm{ppm})\end{array}$ & $\begin{array}{c}C_{\text {out }}^{\max } \\
(\mathrm{ppm})\end{array}$ \\
\hline 1 & $\mathrm{~A}$ & 0.675 & 0 & 15 \\
& $\mathrm{~B}$ & 18.0 & 0 & 400 \\
\hline 2 & $\mathrm{C}$ & 1.575 & 0 & 35 \\
\hline 3 & $\mathrm{~A}$ & 3.4 & 20 & 120 \\
& $\mathrm{~B}$ & 414.8 & 300 & 12500 \\
& $\mathrm{C}$ & 4.59 & 45 & 180 \\
\hline $\mathrm{A}$ & 5.6 & 120 & 220 \\
& $\mathrm{~B}$ & 1.4 & 20 & 45 \\
& $\mathrm{C}$ & 520.8 & 200 & 9500 \\
\hline
\end{tabular}

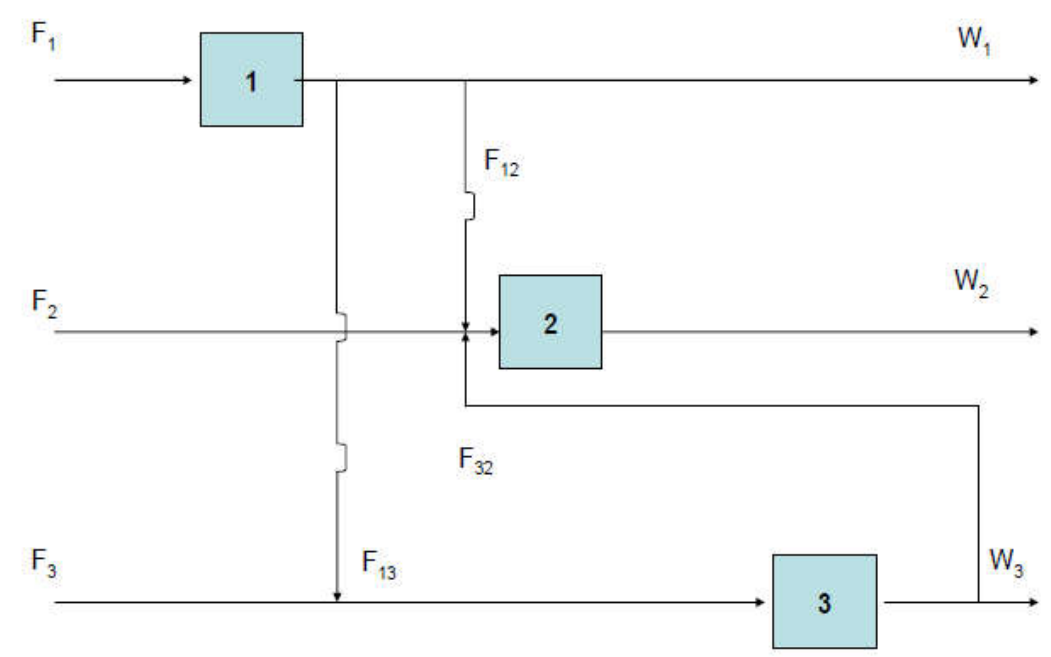

Figure 4. Optimized mass exchanger network 
Tabel 2. Results

\begin{tabular}{cccc}
\hline & Flowrates & \multicolumn{2}{c}{ Contaminant Concentration } \\
\hline Stream & $\begin{array}{c}\text { Values } \\
\text { (ton/h) }\end{array}$ & $C_{i j, \text { out } / \text { in }}^{*}$ & $\begin{array}{c}\text { Values } \\
\text { (ppm) }\end{array}$ \\
\hline$F_{1}$ & 45 & $C_{A 1, \text { out }}$ & 14.99 \\
$F_{2}$ & 8.45 & $C_{B 1, \text { out }}$ & 399.8 \\
$F_{3}$ & 52.18 & $C_{C 1, \text { out }}$ & 34.98 \\
$W_{1}$ & 17.45 & $C_{A 2, \text { out }}$ & 111.27 \\
$W_{2}$ & 33.99 & $C_{B 2, \text { out }}$ & 12499 \\
$W_{3}$ & 55.16 & $C_{C 2, \text { out }}$ & 178.01 \\
$F_{12}$ & 25.06 & $C_{A 3, \text { out }}$ & 43.55 \\
$F_{13}$ & 2.51 & $C_{B 3, \text { out }}$ & 9433 \\
$F_{23}$ & 0 & $C_{C 3, \text { out }}$ & 11.38 \\
$F_{32}$ & 0.062 & $C_{A 2, \text { in }}$ & 298.51 \\
& & $C_{B 2, \text { in }}$ & 43.51 \\
& & $C_{C 2, \text { in }}$ & 0.69 \\
& & $C_{A 3 \text {,in }}$ & 18.37 \\
& & $C_{B 3, \text { in }}$ & 1.61 \\
& & $C_{C 3, \text { in }}$ & 102.1 \\
\hline
\end{tabular}

Figure 4 shows the optimized network for the problem given in Figure 3 ; while Table 2 shows the optimum values of each variable which were the results from computer. We can see from Table 2 that the value of $F_{23}=0$. Therefore the minimum fresh water consumption $=F_{1}+F_{2}+F_{3}=105.63$ ton/h.

The minimum fresh water consumption reported is 105.6 ton/h [9]. However, no detail values were presented for all variables which actually can be found immediately by mass balance equations and optimization formulation using Optimization Toolbox in Matlab.

\section{CONCLUSION}

Mathematical approach based on mass balance has been used in minimization of fresh water consumption for multi contaminant mass exchanger network. The non-linear programming is used for the water allocation problem being studied. The results can be obtained effectively by using Matlab Optimization Toolbox.

\section{Acknowledgements}

The author would like to thank to University of Surabaya and Ministry of National Education. The results in this paper was presented in 19th International Congress of Chemical and Process Engineering CHISA 2010, Prague, Czech Republic [12]. 


\section{REFERENCES}

[1] Miguel Bagajewics, A Review of Recent Design Procedures for Water Networks in Refineries and Process Plants, Computer and Chemical Engineering, Vol. 24, No. 9-10, pp. 2093-2113, 2000.

[2] S.J. Doyle and R. Smith, Targeting Water Reuse with Multiple Contaminants. Trans IChemE, Vol. 75, Part A8, pp.181-189, 1995.

[3] Wang, Y.P., Smith, R., Wastewater Minimisation, Chemical Engineering Science, Vol. 49, No.7, pp.981-1006, 1994.

[4] Wang, Y.P., Smith, R., Wastewater Minimization with Flowrate Constraints, Trans IChemE, Vol. 73, Part B, pp.889-904, 1997.

[5] El-Halwagi, M.M., Pollution Prevention through Process Integration: Systematic Design Tools, Academic Press, California, USA, 1997.

[6] Bao-Hong Li, and Chuei-Tin Chang, A Simple and Efficient Initialization Strategy for Optmizing Water-Using Network Designs, Ind. Eng. Chem. Res., Vol. 46, No.25, pp. 8781 - 8786, 2007.

[7] Perry, R.H., and Green, D.W., Perry's Chemical Engineers' Handbook, 7th Ed., McGraw-Hill, 1997.

[8] M. Saeedi, and M. Hosseinzadeh, Optimization of Water Consumption in Industrial Systems Using Linear and Nonlinear Proggramming, ,Journal of Applied Sciences, Vol. 6, No.11, pp.2386 - 2393, 2006.

[9] Mariano Savelski, and Miguel Bagajewicz, On the Necessary Conditions of Optimality of Water Utilization Systems in Process Plants with Multiple Contaminants, Chem. Eng. Sci, Vol, 58, pp.5349 - 5362, 2003.

[10] Thongchai Srinophakun, Uthaiporn Suriyapraphadilok, and Suvit Tia, Water-Wastewater Management of Tapioca Starch Manufacturing Using Optimization Technique, Science Asia, Vol. 26, No.1, pp 57-67, 2000.

[11] Dewantara, B.S.B., and Miura, J., Optimizing Fuzzy Rule Base for Illumination Compensation in Face Recognition using Genetic Algorithms, Emitter International Journal of Engineering Technology, Vol. 2, No.2, pp. 62-79, 2014.

[12] Agustriyanto, R., Fatmawati, A., and Fransiscus, Y., Nonlinear Programming for Minimization of Fresh Water Consumption in Multi Contaminant Mass Exchanger Network, 19th International Congress of Chemical and Process Engineering CHISA 2010, Prague, Czech Republic. 